\title{
As literaturas de língua portuguesa no ensino básico: breve reflexão ${ }^{1}$
}

\author{
Rosangela SARTESCHI \\ Universidade de São Paulo (São Paulo, Brasil)
}

\begin{abstract}
RESUMO: ESTE TRABALHO PRETENDE FAZER UMA REFLEXÃO SOBRE O ENSINO DAS LITERATURAS DE LÍNGUA PORTUGUESA COLOCADAS EM CONFRONTO, AVALIANDO DE QUE MANEIRA A ATIVIDADE LITERÁRIA INSERE-SE NA DISCUSSÃO DE NACIONALIDADE, DE IDENTIDADE, DE PLURALIDADE E DE DIVERSIDADE. AO INCLUIRMOS A VOZ DAS CULTURAS PERIFÉRICAS, APONTAMOS NÃO SÓ PARA UMA NARRATOLOGIA CRÍTICA DE TRANSFORMAÇÃO E REMODELAÇÃO DOS CÂNONES, COMO TAMBÉM PARA REAVALIAÇÕES CULTURAIS DE NARRATIVAS QUE FORAM MARGINALIZADAS E QUE PERSISTEM NAS FRANJAS OU NOS INTERSTÍCIOS DA SOCIEDADE.
\end{abstract}

ABSTRACT: THIS PAPER REFLECTS ON THE TEACHING OF PORTUGUESE-LANGUAGE LITERATURES IN COMPARATIVE PERSPECTIVE. IT CONSIDERS HOW LITERARY ACTIVITY PARTICIPATES IN DISCUSSIONS OF NATIONALITY, IDENTITY, PLURALITY AND DIVERSITY. BY INTRODUCING PERIPHERAL CULTURAL VOICES INTO OUR DISCUSSIONS WE DO NOT MERELY FLAG UP THE NEED FOR CRITICAL NARRATIVES CONCERNING THE TRANSFORMATION AND REMODELING OF CANONS, BUT ALSO FOR THE CULTURAL RE-EVALUATION OF MARGINALIZED NARRATIVES THAT REMAIN ON THE FRINGES OR IN THE INTERSTICES OF SOCIETY.

PALAVRAS-CHAVE: DIVERSIDADE CULTURAL E EDUCAÇÃO, LITERATURAS AFRICANAS DE LIINGUA PORTUGUESA, LITERATURA AFRO-BRASILEIRA. KEYWORDS: CULTURAL DIVERSITY AND EDUCATION, PORTUGUESE-LANGUAGE AFRICAN LITERATURE, AFRO-BRAZILIAN LITERATURE.

1. O presente texto é uma versão modificada do apresentado no XXII Congresso Internacional da ABRAPLIP em setembro de 2009. 


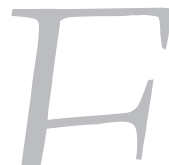

Toda ação principia mesmo é por uma palavra pensada Guimarães Rosa (Grande sertão: veredas)

m 9 de janeiro de 2003 uma nova legislação seria promulgada, fruto de lutas históricas dos movimentos negros brasileiros, indiciando que a igualdade pressuposta no texto da Lei, 9.394/96, de Diretrizes e Bases da Educação deveria ser focalizada sob as lentes de uma diversidade étnica, na medida em que o desconhecimento de grande parte da história brasileira, das produções letradas e das culturas africanas não possibilitava o pleno exercício da cidadania. Nesse sentido, promulga-se a Lei 10.639/03 (modificada posteriormente pelo texto da Lei 11.645/08) que, alterando o texto da LDB, estabelece a obrigatoriedade do Ensino de História e Cultura Afro-Brasileira e Africana nos estabelecimentos oficiais e particulares de ensino fundamental e médio. O texto da lei em seu parágrafo primeiro, do artigo $26 \mathrm{~A}$ detalha que:

$\int 1$ O conteúdo programático a que se refere o caput deste artigo incluirá o estudo da História da África e dos Africanos, a luta dos negros no Brasil, a cultura negra brasileira e o negro na formação da sociedade nacional, resgatando a contribuição do povo negro nas áreas social, econômica e política pertinentes à História do Brasil.

Como ressalta a professora Petronilha Beatriz Gonçalves e Silva, relatora do parecer 003/2004, do Conselho Nacional de Educação, a Lei 10639/03 visa a assegurar o direito à igualdade de condições de vida e de cidadania, assim como garante igual direito às histórias e culturas que compõem a nação brasileira, além do direito ao acesso às diferentes fontes da cultura nacional a todos brasileiros.

Trata-se, segundo a professora da Universidade Federal de São Carlos, de repensar aspectos importantes a respeito das relações étnicossociais no âmbito da educação, na medida em que focalizar e conhecer a diferença, longe de restringir, estabelece novas bases para uma cidadania plena.

Como sabemos, atualmente, a escola ainda é estabelecida a partir de modelos educacionais de regras e normas sociais universalistas. Mesmo tratando com sujeitos que possuem, em suas efetivas particularidades, diversos valores e constructos sociais, nesse modelo de escola prevalece a prática monocultural, baseada em uma visão eurocêntrica: 
Convivem, no Brasil, de maneira tensa, a cultura e o padrão estético negro e africano e um padrão estético e cultural branco europeu. Porém, a presença da cultura negra e o fato de $45 \%$ da população brasileira ser composta de negros (de acordo com o censo do IBGE) não têm sido suficientes para eliminar ideologias, desigualdades e estereótipos racistas. Ainda persiste em nosso país um imaginário étnicorracial que privilegia a brancura e valoriza principalmente as raízes européias da sua cultura, ignorando ou pouco valorizando as outras, que são a indígena, a africana, a asiática (Parecer CNE/CP 003/04).

Nesse sentido, continua a relatora, a transformação da escola seria fundamental nesse processo de aprendizagem e na compreensão necessária para que se possa ver o diferente em suas complexas formas de relações humanas e suas afirmações de significações e re-significações:

A obrigatoriedade da inclusão da História e Cultura Afro-Brasileira e Africana nos currículos da Educação Básica não seria apenas uma decisão circunscrita à área dos currículos, redundando em mais um conteúdo na grade escolar; antes, tratar-se-ia de decisão política, com fortes repercussões pedagógicas, inclusive na formação de professores e na autoestima dos negros, que se veriam representados na literatura, nas artes e na história de forma positiva; o que, de certa maneira, poderia reparar danos que discursos e imagens negativos sedimentaram ao longo de nossa história de país de passado escravista.

A prosseguir na argumentação de Petronilha, não é difícil concordar com a educadora quando ela indica que a relevância do estudo de temas decorrentes da História e Cultura Afro-Brasileira e Africana não diz respeito apenas à população negra, mas a todos os brasileiros, na medida em que devem educar-se enquanto cidadãos atuantes no seio de uma sociedade de indiscutível caráter multiétnico e pluricultural como a brasileira, estando, assim, aptos a contribuir na construção de uma nação democrática.

Trata-se, como se vê, de formar um indivíduo que seja capaz de compreender a diversidade como tal e não na clave da discriminação racial e, dessa maneira, a escola passaria a trabalhar no sentido de promover a valorização da diferença e da diversidade, afirmando positivamente a pluralidade e a singularidade de cada diferente cultura e a não aceitação das desigualdades. É seu papel ratificar essas diferenças como parte de um amplo processo social e cultural. 
Sob essa ótica, a Lei poderá constituir-se em elemento fundamental no processo de construção/reconstrução, de conhecimento/reconhecimento e de valorização das diferentes perspectivas e compreensões concernentes à formação e às configurações da sociedade brasileira contemporânea, auxiliando a desconstruir significações e representações ainda presentes nos conteúdos didáticos e no espaço da escola.

É preciso ter clareza que o Art. 26 A acrescido à Lei 9.394/1996 pretende provocar bem mais do que inclusão de novos conteúdos: sugere que se repensem as relações étnicorraciais, sociais, pedagógicas, procedimentos de ensino, condições oferecidas para aprendizagem e os objetivos tácitos e explícitos da educação oferecida pelas escolas. Nessa medida, é necessário que nos empenhemos no trabalho de transformação do ethos escolar.

Devemos ressaltar neste ponto que não se trata de uma visão ingênua, que encara a Lei 10.639/03 como a resposta a todas as demandas de uma sociedade excludente, mas do reconhecimento das potencialidades que a promulgação da Lei apresenta, na medida em que, pela primeira vez na legislação educacional brasileira, reconhece-se o deficitário conhecimento sobre a cultura e a História da África e dos negros de nosso país e, nessa medida, aponta para os silêncios plenos de significação de nossa História.

Cremos que esse reconhecimento poderá fazer surgir outras atitudes e, a partir do quadro que agora se esboça (ainda que timidamente, admitimos), os sistemas de ensino e os estabelecimentos de diferentes níveis têm ao seu dispor condições mais favoráveis para transformar as demandas da população afro-brasileira em políticas públicas de Estado, ao apontarem para iniciativas com vistas às reparações, ao reconhecimento e à valorização da História e cultura dessa parcela da nossa sociedade. Essas medidas são coerentes com um projeto de escola, de educação e de formação de cidadãos que explicitamente se delineia nas relações pedagógicas cotidianas.

Talvez, no entanto, seja necessária uma saudável desconfiança, fruto do conhecimento da virulência e poder de perpetuação de nossas elites. Ainda assim, não há como negar que o quadro social brasileiro apresenta mudanças substantivas e, dessa maneira, possibilita que se vislumbrem algumas mudanças.

É nesse contexto que se situa a questão do ensino da chamada literatura afro-brasileira e das literaturas africanas de língua portuguesa, sem esquecer, por outro lado, a formação de professores que atuarão nas redes de ensino 
particular e oficial, uma vez que o ensino sistemático de História e Cultura Afro-Brasileira e Africana na Educação Básica, nos termos da Lei 10.639/03, liga-se aos componentes curriculares de Educação Artística, Literatura e História do Brasil.

A introdução de obras e autores africanos e afro-brasileiros na escola inaugura o conhecimento de novos textos e contextos e, dessa forma, remete a uma plurivocidade discursiva com relatos que buscam diálogo com outros relatos, constituindo um espaço de debate, de confronto, além de quebrar a hegemonia dos códigos dominantes do cânone estabelecido.

Como afirma Benjamin Abdala Jr.:

Nas configurações históricas, entre a redução dominante e seu pólo diferente, de abertura ao diverso, forma-se um horizonte macrocontextual. Lá estão os sistemas de expectativas dos autores e dos leitores e a matéria discursiva dos múltiplos campos sêmicos do trabalho humano. Entre um pólo e outro há uma matéria viva de que a historia da literatura precisa dar conta, a partir do estudo dos próprios textos, verificando a historicidade de suas formas, ou, como mostram os procedimentos críticos de Antonio Candido, verificando como os fatores externos interiorizam-se no texto literário. Os múltiplos discursos da vida sociocultural transformam-se em textos que serão literários na medida em que romperem, em termos da teoria da comunicação, com as formas da redundância em função de informações novas (2003, p. 37).

A literatura não é, assim, reflexo mimético das condições sócio-culturais, mas exerce uma função de construção do conhecimento, de criação do mundo como modelador de realidade a qual configura e dá sentido. A abertura para o diverso é, portanto, necessária e premente.

É nessa perspectiva, acreditamos, que as literaturas de língua portuguesa devem ser problematizadas no âmbito da escola: através do contato com escrituras elaboradas a partir de experiências múltiplas e plurais, o estudante terá oportunidade de configurar o presente a partir da reconfiguração do passado. Estão dadas, assim, as condições para que se estabeleça um diálogo entre a memória e o tempo presente, apontando para a construção de um sistema literário e simbólico que reflita genuinamente a sociedade brasileira que o engendra. 
Dessa maneira, apresentar um autor paradigmático como o angolano Luandino Vieira, por exemplo, é proporcionar ao aluno a possibilidade de trabalhar com textos narrativos em que se configura a oralidade angolana por meio de uma língua portuguesa impregnada do quimbundo. Como sabemos, por meio da ruptura com a língua portuguesa padrão, o autor procurou criar uma linguagem literária a partir dos processos e das estruturas linguísticas bantas da região de Luanda; é uma escrita que emerge das falas populares, não se limitando a ser uma recriação artificial e vazia de sentido.

Como nos lembra Antonio Candido (2002, p. 90) ao examinar o regionalismo brasileiro, a abordagem literária do homem posto à margem pode ter um sentido humanizador ou um sentido reificador. Luandino humaniza suas personagens ao construir uma fala angolana "estilizada e convincente, mas ao mesmo tempo literária, esteticamente válida": as vozes do musseque surgem na sua escrita, evocando o plurilinguismo de noção bakhtiniana. Assim entendido, o plurilinguismo significa vozes sociais que se respondem mutua e dialeticamente, em permanente tensão no interior do texto.

A opção pelo plurilinguismo para representar a diversidade, as perspectivas múltiplas e as diferentes falas sociais é fator de criação e escolha consciente, funcional e estética do artista, demonstrando a ética pretendida. Essa escolha transforma a narrativa no locus do desenvolvimento e do convívio mútuo de várias línguas nacionais, de várias "falas".

Esse dialogismo plurilíngue que se estabelece, ainda segundo Bakhtin, demonstra a artificialidade da barreira entre texto e contexto, entre "dentro" e "fora", pois o que existe, na verdade, é a permeabilidade imanente entre os dois.

O texto é, portanto, o "campo de batalha" das relações sociais de poder, representado pelo reconhecimento de que as várias vozes representam posições socioideológicas diferentes, cuja relação conflitiva existe no próprio cerne da mudança da linguagem.

É o que ocorre, por exemplo, nos três contos do livro Lunanda, em que o tom oralizado plurilíngue e de ruptura prende o leitor que se deixa seduzir pelas falas que se articulam em tensão dialética na vida textualizada de pessoas e circunstâncias próprias daquele universo popular. Nessa polifonia se dá voz aos marginalizados, aos oprimidos, aos periféricos e, por isso, é o que a diferencia do discurso monológico, que é o discurso autoritário, univocal e que tem por objetivo calar a voz do outro. 
Nessa instância, outro exemplo substantivo a ser considerado no âmbito escolar é o romance Mayombe, de Pepetela. Entre as variadas possibilidades de análise, destacam-se o estudo do narrador e a sua importância para a construção do sentido daquela narrativa. Ao dar voz a personagens que são periféricas na história real, o autor angolano adota postura claramente ideológica que pretende contestar as verdades oficiais. Cada uma das personagens interpreta o mundo à sua volta sob seu próprio prisma e não há um ponto de vista que se sobreponha a outro; todos estão, ainda que em tensão dialética, em harmoniosa plurivalência.

É na multiplicidade de vozes e consciências independentes e autônomas, de acepção bakhtiniana, que essa identificação se constrói: a narrativa é exemplo de que só existem verdades no plural e jamais haverá uma só verdade; e raramente existe a falsidade per se, apenas as verdades alheias.

Em Mayombe, as diversas vozes substituem, de maneira explícita, a voz do narrador uno que se exime, assim, de ser portador único de sua "verdade única"; cabe às vozes diversas e ao próprio leitor interagirem nesse mundo que se manifesta em eterna e constante transformação, como se vê anunciado: " $\mathrm{Eu}$, narrador, sou...” (PEPETELA, 1982, p.32)

O caos da realidade criada convida o leitor a ser ele também agente dessa construção, obrigando-o a interagir em um mundo que se manifesta em eterno devir, o que, por conseguinte, instaura, paralelamente, o diálogo entre obra e leitor.

O "eu-sujeito" vário de Pepetela reconhece sua fraqueza e sua própria impotência e a supremacia do mundo como objeto emerge da multiplicidade dos agentes no romance.

Por outro lado, em termos de história literária, a introdução de textos africanos de língua portuguesa na escola propiciaria que se refletisse também sobre a questão da comunicação dos sistemas literários do mundo de língua portuguesa. É inegável que a projeção de imagens do Brasil contribuiu para a formação de um pensamento nacionalista nos países de língua oficial portuguesa, ensejando novos parâmetros e alternativas ao modelo do colonizador.

Em Cabo Verde, por exemplo, o grupo ligado à Claridade (1936) e, depois, à Certeza (1944) anunciava através da literatura a construção da cabo-verdianidade, de maneira que escritores e intelectuais projetavam um "esforço criador nos grandes segmentos que representavam ou simbolizavam a parte viva da 
sua pátria, ou seja, aquela que não dotava os critérios e os padrões que serviam ao colonialismo". (FERREIRA,1987, p. 33)

Assim, em Oswaldo Alcântara, com seu Itinerário de Pasárgada (1946), é visível a escalada da "cabo-verdianidade" que estabelece um importante diálogo com o famoso poema de Manuel Bandeira, de forma que se poderia mesmo afirmar que o texto brasileiro apresenta-se como o alicerce sobre o qual se assenta uma parte fundamental da nova poética do arquipélago:

Saudade fina de Pasárgada

Em Pasárgada eu saberia

onde é que Deus tinha depositado

o meu destino

E na hora em que tudo morre...

Cavalinhos do Nosso Senhor correm no céu;

a vizinha acalenta o sono do filho rezingão;

Tói Mulato foge a bordo de um vapor;

o comerciante tirou a menina de casa;

os mocinhos da minha rua cantam:

indo eu, indo eu

a caminho de Viseu...

$\mathrm{Na}$ hora que tudo morre,

esta saudade fina de Pasárgada

é um veneno gostoso dentro do meu coração.

Mas, como ressalta Maria Aparecida Santilli (2003, p. 151), "a rota de Pasárgada pela literatura cabo-verdiana não se fará por um único diapasão, por uma nota só”. Ou, em outros termos, haverá outras réplicas no diálogo literário estabelecido entre Cabo Verde e o Brasil. Ainda que pela via da negação, no poema "Anti-evasão", de Ovídio Martins, que enfatiza o seu país como o espaço da luta para a realização da utopia, o texto de Bandeira comparece: 
Pedirei

Suplicarei

Chorarei

Não vou para Pasárgada

Atirar-me-ei no chão

e prenderei nas mãos convulsas

ervas e pedras de sangue

Não vou para Pasárgada

Gritarei

Berrarei

Matarei

Não vou para Pasárgada

Como afirmávamos, a inclusão de textos de autores africanos de língua portuguesa no currículo escolar pode permitir uma leitura mais ampla do fenômeno literário, seja no que tange à relação entre oralidade/escrita, entre história e ficção, seja na revisão da história literária de maneira a que se conheça o diálogo que se estabeleceu entre autores brasileiros e africanos. Já em termos da reflexão sobre texto e contexto, aquela inclusão pode levar à reflexão sobre de que maneira a atividade literária insere-se na discussão da nacionalidade, da identidade e da pluralidade, buscando-se afirmar e firmar diferenças em uma plataforma comum aos falantes de língua portuguesa.

É nessa esfera - a da construção identitária - que, segundo entendemos, é bastante pertinente falar de literatura negra ou afro-brasileira, pois o discurso dessa literatura é o discurso da identidade ou, ainda, da reconstrução identitária. A importância da emergência do eu-enunciador que se quer negro e assume ser sujeito da sua própria escritura assinala, como nos lembra Zilá Bernd, uma ruptura definitiva com o discurso que negava os negros, apontando para a problematização do seu papel na configuração de um sistema literário produzido por uma sociedade excludente como a brasileira.

Nesse sentido, pode-se dizer que a leitura de textos afro-brasileiros pode ser conduzida de forma a estabelecer uma relação do "leitor-sujeito" com o 
"dar sentido" e contribuir para novas leituras de mundo em que as questões identitárias tenham relevo. A seleção deverá apontar, portanto, para textos em que a construção de uma imagem positiva do negro é destacada e, a partir deles, apontar as possibilidades que se abrem quando chamamos à cena textos plenos de radicalidade estética e ética.

Dentre os vários exemplos possíveis, destacar-se-ia a poesia de Solano Trindade, que se apresenta como uma literatura de resistência, construindose a partir da cultura africana que sobreviveu no espaço para onde os negros foram compulsoriamente transplantados:

\section{Orgulho Negro}

Eu tenho orgulho de ser filho de escravo...

Tronco, senzala, chicote,

Gritos, choros, gemidos,

Oh! que ritmos suaves,

Oh! como essas cousas soam bem

Nos meus ouvidos...

Eu tenho orgulho em ser filho de escravos...

Como podemos perceber pelo exemplo aqui destacado, sua poética é construída a partir de uma quebra dos estereótipos do lamento sobre a escravidão que ressoam em nossa literatura desde o romantismo, de modo que o eu lírico faz ouvir a sua voz que subverte os termos da história ao afirmar o orgulho de sua origem de trabalho e sofrimento.

Como afirma Zilá Bernd (1992, p. 46), essa poesia também é marcada por uma busca identitária contínua, "que não é apenas individual ou nacional, mas solidária com todos os negros da América...", como vemos em:

Quem ta gemendo?

Quem ta gemendo

Negro ou carro de boi?

Carro de Boi geme quando quer.

Negro, não. 
Negro geme porque apanha.

Apanha pra não gemer...

Gemido de negro é cantiga

Gemido de negro é poema...

Geme na minh'alma,

A alma do Congo,

Do Níger da Guiné,

De toda a África enfim...

A alma da América...

A alma Universal...

Quem ta gemendo

Negro ou carro de boi?

No poema, ecos da Negritude se fazem presentes e, dessa forma, a partir da identidade, alarga-se a geografia e a história, possibilitando outras leituras do negro, não mais como "animal de carga", mas sim como "alma universal", isto é, atingindo uma dimensão cósmica.

Outra experiência a ser apontada é a da ligada ao Cadernos Negros, a qual nos remete não apenas aos poemas e contos publicados pelo grupo Quilombhoje, como também às questões do cânone, já que, apesar de estar há três décadas produzindo, o grupo que os realiza, assim como o Cadernos, é pouco conhecido do grande público. Nesse sentido, as questões fundamentais que se colocam é a desconstrução de uma tradição literária que exclui a produção da população negra, a circulação e a recepção de seus textos e a respectiva marginalidade dessa produção.

Além dessa perspectiva, a produção poética do grupo, que tem um programa estético-ideológico muito bem definido, em que se destaca a busca de conscientização do negro através da literatura, constitui-se como espaço de eficiente resistência, fortalecida com a redescoberta das culturas africanas e de traços de uma história que foi silenciada, uma arma na luta contra o racismo, a exclusão e as desigualdades, poética fincada na valorização da memória das tradições que se transmitem de geração a geração. 
É necessário destacar, ainda, que além do inquestionável compromisso ideológico, em que o homem negro surge como sujeito da história e do devir, os autores negros brasileiros demonstram preocupação com o apuro estético de sua produção, pois como afirma Benjamin Abdala Jr. (1989, p. 22) "a radicalidade 'exterior' do escritor engajado só se efetiva concretamente num engajamento de radicalidade literária. Ao escritor participante ou militante é solicitado que ele tenha consciência crítica dos processos literários que utiliza." Um exemplo a destacar é o poema de "Negroesia", de Cuti (2007, p. 29):

\section{Negroesia}

enxurrada de mágoas sobre os paralelepípedos

por onde passam carroções de palavras duras

com seus respectivos instrumentos de tortura

entre silêncios

augúrios de mar e rio

o poema acende seus pavios

e se desata

do vernáculo que mata

ao relento das estrofes

acolhe os risos afros

embriagados de esquecimento e suicídio

no horizonte do delírio

e do âmago de desencanto contesta as máscaras lançando explosivas metáforas pelas brechas dos

$$
\text { poesídios }
$$

contra o arsenal do genocídio.

Nessa poesia, vemos como a ação prática é mediatizada por refinados códigos artísticos, expressando a luta das ideologias e mostrando claramente uma sociedade estratificada em contínua tensão dialética. É essa tensão que deverá, do ponto de vista ideológico, desencadear conflitos que propiciarão a transfor- 
mação histórica de que fala Lukács. É a perspectiva que aponta para a produção artística com sua função formadora da construção de uma nova sociedade.

Como tentamos deixar claro, a implementação dessa variedade de disciplinas atinentes à Lei 10.639/03 e 11.645/08 pode contribuir, indubitavelmente, para o estabelecimento de um processo de construção e reconstrução, de conhecimento e reconhecimento e de valorização das diferentes perspectivas e compreensões concernentes à formação e às configurações da sociedade brasileira contemporânea, desconstruindo as significações e representações presentes nos conteúdos didáticos e no espaço da escola.

Em suma, no âmbito dos estudos literários, por meio das relações que se estabelecem entre autor/obra/contexto/leitor, confirmam-se processos em que a pluralidade e a diversidade são elementos imprescindíveis para a construção de novas identidades, ou seja, produção e recepção de texto são operações das quais a ideologia não pode ser desconsiderada. E a escola, espaço de aprendizado dessas práticas, pode ensinar não apenas a decodificar letras, mas também - com a inclusão de novos textos em seu repertório - a decodificar realidades.

\section{Referências bibliográficas}

ABDALA JR, B. De vôos e ilhas: literatura e comunitarismos. Cotia: Ateliê Editorial, 2003.

ABDALA JR., B. Literatura, história e politica. São Paulo: Ed. Ática, 1989.

BAKHTIN, M. Problemas da poética de Dostoiévski. Rio de Janeiro: Forense Universitária, 2002.

BERND, Z. Poesia Negra Brasileira: Antologia. Porto Alegre: AGE/IEL/IGEL, 1992

CANDIDO, A. A literatura e a formação do homem. In: Textos de intervenção (seleção, apresentação e notas de Vinícius Dantas). São Paulo: Duas Cidades/Editora 34, 2002.

CONSELHO NACIONAL DE EDUCAÇÃO. Parecer CNE/CP 003/2004. Relatora: Petronilha Beatriz Gonçalves e Silva: Brasília, 2004.

CUTI. Negroesia. Antologia Poética. Belo Horizonte: Mazza edições, 2007.

FERREIRA, M. Literaturas africanas de expressão portuguesa. São Paulo: Ed. Ática. 1987.

FERREIRA, M. (org). No reino de Caliban. Antologia panorâmica da poesia africana de expressão portuguesa I - Cabo Verde e Guiné Bissau. Lisboa: Seara Nova, 1975. 
PEPETELA. Mayombe. São Paulo: Ed. Ática, 1982.

SANTILLI, M.A.C.B. Paralelas e tangentes: entre literaturas de língua portuguesa. São Paulo: Centro de Estudos Portugueses/USP, 2003. Via Atlântica.

SECAD/MEC. Orientações e ações para a educação das relações étnico-raciais. Brasília: SECAD, 2006.

TRINDADE, S. Poemas Antológicos. São Paulo: Nova Alexandria, 2008.

VIEIRA, J. L. Luuanda. São Paulo: Companhia das Letras, 2006.

Recebido em 12 de julho e aprovado em 5 de setembro de 2010. 